Jari Lavonen, PhD, is Professor of Physics and Chemistry Education and Director of the Subject Teacher Education Section at the Department of Applied Sciences of Education, University of Helsinki. Reijo Byman, PhD, Kalle Juuti, PhD, and Anna Uitto, $\mathrm{PhD}$ are University Lecturers at the same department. Veijo Meisalo, PhD, is Professor emeritus. In addition to the ROSE -FIN survey, the group is active in several research projects emphasising ICT use in science education.

\section{JARI LAVONEN}

Jari.Lavonen@helsinki.fi

REIJO BYMAN

Reijo.Byman@helsinki.fi

KALLE JUUTI

Kalle.Juuti@helsinki.fi

\section{VEIJO MEISALO}

Veijo.Meisalo@helsinki.fi

ANNA UITTO

Anna.Uitto@helsinki.fi

Department of Applied Sciences of Education

University of Helsinki, Finland

\title{
Pupil Interest in Physics: A Survey in Finland
}

\begin{abstract}
Factors interrelating with interest in physics learning are gender, perceived relevance, contents and contexts of physics, and teaching methods. Finnish ninth grade secondary school pupil interest in physics in different contexts was investigated with a survey conducted in connection with the international ROSE project. The sample consisted of 3626 pupils (median age 15) in 61 schools. Means of all items that belong to school physics context for both girls and boys were under the middle of the scale. The most interesting things (especially for girls) were connected with human being and the less interesting (especially for girls) were connected in artefacts and technological processes. Astronomical context was rather interesting for both genders. The main message of the study is that interesting new curricular approaches and textbooks can be developed by combining technological and human or astronomical contexts.
\end{abstract}

\section{INTRODUCTION}

There is a long tradition from the 1960s onwards to the study of pupil interest, behaviour, achievement, and attitudes ('pupil voice') towards physics (Sjøberg, 2000; Osborne, Simon, \& Collins, 2003; Bennett, 2003). Research has shown that pupils will study and learn physics better and, moreover, choose physics courses in upper secondary school if they are interested in it. Modern interest research (for a review, see Hidi, Renninger, \& Krapp, 2004) has also shown that interestbased motivation to learn has positive effects both on studying processes and on the quantity and quality of learning outcomes. Thus, because pupils' interest in physics learning is so important to future involvement in the subject, it is useful to know how physics teaching should be developed and learning materials designed to be more interesting for pupils. In the following we, firstly, review the literature of interest and secondly, we highlight aspects of interest in physics learning.

\section{Interest as a concept}

Intrinsic motivation seems to be the optimal motivation to learn. It is supposed to have positive effects on learning (e.g., Deci \& Ryan, 1985). If compared to extrinsic motivation which is instrumental in nature, intrinsic motivation leads to intensive and persistent studying activities and through that it improves the quality of learning. Pupils who are intrinsically motivated to learn about a topic are apt to engage in studying activities they believe will help them to learn. These 
kind of studying activities include, for instance, focusing carefully on the instruction and using adequate studying (learning) strategies for the topic. Several researchers (Schiefele, 1999; Krapp, 2002) have presented that interest is a central precondition for intrinsic motivation. Intrinsically motivated activities are activities which people do naturally and spontaneously when they follow their inner interests. According to Ryan and Deci (2000, p. 71), "people will be intrinsically motivated only for activities that hold intrinsic interest for them, activities that have the appeal of novelty, challenge, or aesthetic value." Interest seems to be a central concept when we try to understand the functional relationship between motivation and learning. However, interest differs form other motivational variables in three aspects: it is content specific and a result of an interaction between a person and his or her environment, and, moreover, it has both cognitive and affective aspects (Hidi, Renninger \& Krapp, 2004). Nevertheless, relatively little is known about how interest in school subjects develops, especially for pupils who don't have definite vocational goals.

Traditionally there have been two major points of view from which interest has been approached (Krapp, 2003). One is interest as a characteristic of a person and the other is interest as a psychological state aroused by specific characteristics of the learning environment. Traditionally, the former approach has been termed topic interest or personal interest and the latter has been called situational interest. Unlike personal interest, which is always specific to an individual, situational interest is assumed to be spontaneous, fleeting, and shared among individuals. Personal interest is topic specific, persists over time and can be subdivided into latent and actualized interest (Schiefele, 1991; 1999). According to Hidi (1990), personal interest develops slowly and tends to have long-lasting effects on a person's knowledge and values, whereas situational interest is an emotional state that is evoked suddenly by something in the immediate environment and that may have only a short term effect on an individual's knowledge and values. Situational interest is aroused as a function of the interestingness of the content and context and partially under the regulation of teachers (Schraw, Flowerday \& Lehman, 2001).

Several researchers (Mitchell, 1993; Krapp, 2002) have made a distinction between catching and holding situational interest. Catching or triggering refers to variables that initially stimulated pupils to become interested in a specific topic (cf. interestingness). Holding interest refers to variables that empower pupils with a clear goal or purpose. Mitchell (1993) has suggested that essential to the shift from catching to holding a pupil's situational interest are learning conditions that make the content of learning meaningful and personally relevant to pupils. Krapp (2002) has suggested that in certain conditions situational interest can transform into personal interest. According to him, this ontogenetic transformation is a two-step mental process where internalization and identification have a central role. (1) Catching and holding the situational interest for the first time. (2) Through an internalization process this situational interest can develop into individual or personal interest and, therefore, motivation and interest is no longer seen as simply an individual variable. From the viewpoint of physics learning, the critical part of situational interest seems to be how to hold it long enough to lead to a motivation to study and the activities of studying. Ainley, Hidi and Berndorff (2002) have suggested that pupil's affective response to teaching or learning material forms the link between interest and learning. According to this thinking, interest is related to affective response, affect is related to persistence in studying, and studying is related to learning. As a summary, interest can be seen as an integrated component of an interrelated network of psychical, social, and physical factors in a certain learning situation (Volet \& Järvelä, 2001).

Schiefele $(1991 ; 1999)$ suggested that interest is a content-specific concept as well as a facilitator, and that it consists of two kinds of valences: feeling-related and value-related valences. Feelingrelated valences are feelings that are associated with a topic, for instance, feelings of enjoyment and involvement. Value-related valences refer to the attribution of personal significance to a topic. Also Krapp (2002) has presented the development and maintenance of personal interest as being dependent on two functional systems, resembling Schiefele's valence distinctions that primarily act independently of each other. According to Schiefele's (1992, p. 154) valence distinction he reinter- 
preted interest "as a context-specific or topic-specific motivational characteristic of personality, which is composed of intrinsic feeling-related and value-related valences." Krapp (2003) has also assumed that the fulfilment of so-called basic psychological needs for competence, autonomy, and social relatedness are important for the development of interest.

Sansone, Wiebe and Morgan (1999) have proposed that pupils react in three ways when they face an uninteresting task. Firstly, they can quit the task. Secondly, if a pupil is highly motivated to maintain performance, he or she may persist in doing the task, although he or she suffers from stress-related effects. Third, a pupil can persist in doing the task and attempt to transform the activity into something more interesting. As a summary, pupils can self-regulate interest and, therefore, it is valuable for teachers to know that he or she can have an affect on pupils' interest through regulation or choosing of tasks.

Lepper and Henderlong (2000) have emphasized that arousal of interest and intrinsic motivation is not possible if the pupil does not have a minimal level of competence. Thus, traditionally, studying physics has been motivating for gifted pupils who enjoy learning about natural phenomena, experimenting and solving problems. On the other hand, pupils who experience physics as difficult do not even try to learn it and they loose interest in the subject very quickly. That is, if a pupil does not understand physics, it unrealistic to believe that he or she will develop an interest in it.

Computer and video game research has clarified that there are some essential features for intrinsically motivating activities. They, for example, incorporate an optimal challenge, have an appropriate goal and uncertain outcomes, provide clear, constructive, and encouraging feedback, and offer elements of curiosity, and fantasy (Malone \& Lepper, 1987). Cordova and Lepper (1996) have shown that also contextualization, personalization and choice increase students' interest and intrinsic motivation.

\section{Interesting contents and contexts}

Physics education research has identified factors that interrelate with interest in physics learning: nationality, gender, relevance for further studies or occupation, interest in the contents of physics, interest in a context where certain physics content or topics are met, interest and enjoyment in an activity type or the teaching methods used, perceived achievement, level of difficulty, and appreciation of the topic (Simon, 2000; Stokking, 2000). For example Sjøberg (2000) explored the effect while presenting the same content in different context. He found that the context in which science ideas are taught, rather than the ideas themselves, is an important influence on interest.

One important goal in the development of physics education has been to bridge the gender gap in physics. There are two main reasons for this: firstly, an equal number of women and men in science and technology-related occupations would promote a more equal society, and secondly, in general, students are choosing physics less and less. Girls are often seen as an untapped resource (Osborne, Simon, \& Collins, 2003). In principle, two possible approaches to take when aiming to increase the number of girls involved in physics have been suggested. The first is to change girls' attitudes, interests, or behaviours. An example of this would be to conduct a marketing campaign advertising the technology industry, to increase the perceived attractiveness of the field. The second approach is to change the content or context, the idea being that learning should be made more interesting (cf. Biklen \& Pollard, 2001).

In recent interest research, the role of context has gained increasing attention (Volet \& Järvelä, 2001). In the framework of science education, context is especially emphasised in context-based approaches (e.g. Science - Technology - Society (STS) Movement, Applications-led Approach, Science for All Movement, Scientifc Literacy). Of course there are differences between approaches and the term 'context-based' is more common in Europe, whilst 'STS' is more common in North 
America. In these approaches contexts and applications of science are used as the starting point for the development of scientific ideas. In the context-based approaches pupils might become familiar with the electromagnetic spectrum through learning about medical techniques for seeing inside the body, or explore the views of different members of a community on the impact of locating a chemical industry nearby. This contrasts with more traditional approaches, which cover scientific ideas first, and conclude with a brief mention of applications (Bennett, Hogarth \& Lubben, 2003).

In recent discussion environmental aspects include STS Movement and instead of STS, Science - Techonology - Society - Environment (STSE or STES) Movement is often discussed. Hodson (2003) provides a categorisation of pedagogical approaches involved in STSE education and suggests that there are four "levels" of commitment to STSE education that are found in science education: cultural aspects of science and technology; wealth, power and other aspects affecting decisions about scientific and technological development; development of one's own views and value positions; and preparing for and taking action (p. 655).

From the point of view of this research astronomy can be understood also as a context for physics education. However, there is limited research about physics education in an astronomical context, although, pupils' learning and attitudes to astronomy have been researched (Bailey \& Slater, 2003). For example, astrobiology, the interdisciplinary study of life in the universe has been recognised as a way to increase pupils' interest in astronomy and also in science (Zeilik, Bisard \& Lee, 2002).

According to Parker and Lepper (1992), meaningful and appealing fantasy contexts enhance interest and promote learning. Thus, some items in the questionnaire, used in this research, are grouped and named "Fantasy context" inspired by the usage in the framework of computer game research. Based on this research, it is known that characteristics that make an (learning) activity or a game motivational and compelling include fantasy and curiosity (Asgari \& Kaufman, 2004). Therefore, one way to make learning motivating is to present the material to pupils either in an imaginary context which is familiar to them or in a fantasy context which is emotionally appealing for the learner. Malone and Lepper (1987) define fantasy as an environment that "evokes mental images of physical or social situations not actually present" (p.240).

One context in the empirical part of this research is named "School physics context". In Finland, physics, chemistry and biology are taught separately at the lower secondary school level and the national curriculum as well as schoolbooks emphasise the basic concepts and physical laws, as well as (technical) applications of them, and, moreover, experimental nature of physics. Accordingly, the School physics context means topics discussed in lower secondary school physics. In the national framework curriculum valid when the data were collected (NBE, 1994) it is for example stated:

\section{When studying Physics, the pupil}

-learns basic terms, principles, and laws and models that relate to physical phenomena; -can discuss things pertaining to the field and phenomena in Physics and can also apply Physics knowledge to issues concerning nature and the environment ...

The main contents of Physics have been grouped into five different themes: structures and systems; interactions; energy; processes; and method of scientific inquiry.

In the present study, we focus on Finnish lower secondary school pupils' interests (median age 15) in certain physics contents and contexts. The research question is:

Which are the physics contents and contexts that Finnish lower secondary school boys and girls are interested in? 


\section{MetHOD}

In order to answer the research question, we organised a survey alongside the Finnish contribution to the international comparative research project ROSE (The Relevance Of Science Education, here ROSE INT) aiming to shed light on factors of importance to the learning of science and technology in comprehensive school (Schreiner \& Sjøberg, 2004). The ROSE INT questionnaire has been prepared through international cooperation so that the findings could help teachers and researchers to make science education and learning more interesting. However, in this study, only a small number of items from the original ROSE questionnaire were used to examine student/pupil interest in physics, thus we refer here to the national version of the questionnaire, ROSE FIN. We have reported other parts of the survey elsewhere (e.g. Uitto, Juuti, Lavonen \& Meisalo, 2004) and we will further continue our analysis of the survey data.

The items analysed in the present paper measured mainly pupils' interest in school physics, astronomy and physics in an astronomical context, technology and physics in a technological or STS context. In the questionnaire, there were also some items exploring interests in phenomena not easily or not at all explained by school physics such as those related to horoscopes and UFOs (fantasy context).

In the questionnaire, pupils were asked to state "How interested are you in learning about the following?" Pupils answered by ticking the appropriate box on a four-point Likert scale, the extreme categories being Not interested and Very interested. The responses were scored 1, 2, 3 and 4. Even if the scale is an ordinal one, it is easier to discern the findings when they are presented as means to each item. The teachers or headmasters reported no problems in organising the survey.

Because there were many items connected to physics contents or contexts in the ROSE FIN questionnaire, we decided to group the items thematically to present the findings. Items can be grouped, e.g., into different content areas or contexts of physics. From the point of view of research questions, we decided to divide the items into four groups: (1) Fantasy context, (2) Astronomical context, (3) STS context, and (4) School physics context. However, there is no absolute way to group items. The present grouping reflects Finnish National Framework curriculum and research literature concerning interest. It is not clear to which group a certain item should be placed. For example the item "Electricity, how it is produced and used in the home" can be placed to the school physics context (first part of the sentence) or to the technology (last part of the sentence).

Altogether, 75 lower-secondary schools were randomly selected from the list of Finnish-language comprehensive schools in Finland. In each of these schools, about 65 pupils were asked to answer the survey, which meant about three classes from each school. In total, we had 4954 pupils participating in the survey. The questionnaire was sent to the schools in spring 2003, and the school principals were asked to organise the survey and return the completed questionnaires. The national and international purposes of the survey were carefully explained on a cover sheet. Altogether, 26 reminders (37\% of the selected schools) were sent to those principals who had not returned the survey in time. The survey was answered by 3626 pupils (1772 girls) in 61 schools representing $81 \%$ of the selected schools. The number of pupils answering the survey was $7 \%$ of the whole age cohort. Thus, the external validity of the present research could be evaluated to be quite high and the sample represents the population quite well. However, we must remember that there are no 'average' pupils. There are always boys and girls that are interested in one issue more than in another and, correspondingly, there are boys and girls that are totally uninterested in a particular issue. Therefore, saying "girls want to..." or "boys are not interested..." we don't mean straightforward generalisations that all girls or all boys share certain interests, but as a group there is a tendency towards that interest. 
The pupils' answers were read by optic scanners and data was saved to SPSS. The data was cleaned in SPSS by looking carefully at all lines and for example running frequency tables for all variables to search for values outside the 'legal' range.

\section{RESULTS}

To evaluate the internal consistence of the context scales, we calculated Cronbach's Alpha $(\alpha)$ for each scale. Alphas were between 0.81 and 0.89 , thus confirming that the contexts scales were internally consistent. The resulting Alphas coefficients for each scale are presented in the table headings of Tables $1-4$.

Tables 1 to 4 show the findings in a way that the group of items which the pupils considered the most interesting is presented first and the one that they considered the least interesting last. Each table shows the mean $(M)$ of the items and separate means for girls $\left(M_{\mathrm{g}}\right)$ and boys $\left(M_{\mathrm{b}}\right)$ as well as standard deviations $\left(S . D_{\mathrm{g}}\right.$ and $\left.S . D_{\mathrm{b}}\right)$. Within each group, the items have been arranged according to girls' preference rate. The middle point of the scale corresponds to 2.5. Consequently, in this case it is possible to conclude that when the mean falls below 2.5, the majority of the pupils were not interested in the subject matter and in contrast, when the mean is above 2.5 , the majority of the pupils were interested.

The means of the boys' and girls' distributions have been compared using the Independent-Samples t-test (two-tailed) and as an additional check, we tested the power of the difference using Cohen's $d\left(d=M_{\mathrm{g}}-M_{\mathrm{b}} / S . D\right.$. pooled, where S.D. pooled $=\sqrt{ }\left[\left(S . D_{\mathrm{g}}{ }^{2}+S . D_{\mathrm{b}^{2}}\right) / 2\right]($ Cohen, 1988). The Independent-Samples t-test procedure compares means for two groups of cases. Cohen's d measures the effect size for the difference between boys and girls: no effect at $d<0.2$, small effect at $0.2 \leq d$ $<0.5$, moderate effect at $0.5 \leq d<0.8$, and large effect at $d \geq 0.8$.

Among the four groups of items, the pupils, and especially girls, were most interested in fantasy context, such as the interpretation of dreams, horoscopes and UFOs. Among the sciences, pupils were most interested in topics related to astronomy and secondly in topics related to technology or issues in STS context. The pupils were least interested in topics related to school physics context. To the items in the school physics and STS context, boys had at least some interest, but girls, as a group, had little interest.

Table 1. Pupils' interest in a fantasy context $\left(M=2.67, M_{g}=2.93, M_{b}=2.42, \alpha=0.88\right)$.

\begin{tabular}{|c|c|c|c|c|c|c|}
\hline & \multicolumn{2}{|c|}{ Girl } & \multicolumn{2}{|c|}{ Boy } & \multirow{2}{*}{$\begin{array}{ll}t \\
\text { 1) }\end{array}$} & \multirow[t]{2}{*}{$d$} \\
\hline & $M_{\mathrm{g}}$ & $S . D_{\mathrm{g}}$ & $M_{\mathrm{b}}$ & S. $D_{\mathrm{b}}$ & & \\
\hline $\begin{array}{l}\text { Why we dream while we are sleeping, and } \\
\text { what the dreams may mean }\end{array}$ & 3.37 & .83 & 2.56 & 1.01 & $684.2^{* * *}$ & $0.74^{C}$ \\
\hline $\begin{array}{l}\text { Thought transference, mind-reading, sixth } \\
\text { sense, intuition, etc. }\end{array}$ & 3.12 & 1.00 & 2.51 & 1.06 & $307.3^{* * *}$ & $0.49^{\mathrm{B}}$ \\
\hline Life and death and the human soul & 3.04 & .96 & 2.36 & 1.03 & $413.3^{* * *}$ & $0.56^{\mathrm{C}}$ \\
\hline $\begin{array}{l}\text { Ghosts and witches, and whether they may } \\
\text { exist }\end{array}$ & 2.77 & 1.11 & 2.20 & 1.09 & $243.8^{\star * *}$ & $0.42^{\mathrm{B}}$ \\
\hline $\begin{array}{l}\text { Astrology and horoscopes, and whether the } \\
\text { planets can influence human beings }\end{array}$ & 2.77 & 1.07 & 2.05 & .99 & $426.8^{* * *}$ & $0.56^{\mathrm{C}}$ \\
\hline
\end{tabular}

\footnotetext{
1) ns $\mathrm{p}>0.05,{ }^{*} \mathrm{p}<0.05,{ }^{* *} \mathrm{p}<0.01,{ }^{* * *} \mathrm{p}<0.001$

2) A no effect $(d<0.2),{ }^{\mathrm{B}}$ small effect $(0.2 \leq d<0.5),{ }^{\mathrm{C}}$ moderate effect $(0.5 \leq d<0.8),{ }^{\mathrm{D}}$ large effect $(d \geq 0.8)$
} 
Cohen's $d$ indicated moderate effect size for following themes: dreams, soul, and horoscopes $\left(M_{\mathrm{g}}\right.$ $\left.>M_{\mathrm{b}}\right)$ as well as use of satellites, function of TV and radio, atom bomb, and nuclear power plant $\left(M_{\mathrm{b}}>M_{\mathrm{g}}\right)$.

Table 2. Pupils' interest in an astronomical context $\left(M=2.49, M_{g}=2.46, M_{b}=2.52, \alpha=0.89\right)$.

\begin{tabular}{|c|c|c|c|c|c|c|}
\hline & \multicolumn{2}{|c|}{ Girl } & \multicolumn{2}{|c|}{ Boy } & \multirow{2}{*}{$\begin{array}{l}t \\
\text { 1) }\end{array}$} & \multirow{2}{*}{$\begin{array}{l}d \\
2)\end{array}$} \\
\hline & $M_{\mathrm{g}}$ & $S . D_{\mathrm{q}}$ & $M_{\mathrm{b}}$ & S. $D_{\mathrm{b}}$ & & \\
\hline How it feels to be weightless in space & 3.04 & 1.00 & 2.90 & 1.02 & $15.3^{* * *}$ & $0.11^{\mathrm{A}}$ \\
\hline The possibility of extraterrestrial life & 2.84 & 1.04 & 2.73 & 1.06 & $8.7^{* *}$ & $0.09^{\mathrm{A}}$ \\
\hline $\begin{array}{l}\text { Black holes, supernovas and other spectacular } \\
\text { objects in outer space }\end{array}$ & 2.71 & 1.04 & 2.67 & 1.06 & $1.4^{\mathrm{ns}}$ & $0.03^{A}$ \\
\hline Stars, planets and the universe & 2.69 & 0.94 & 2.49 & 1.03 & $36.9^{* * *}$ & $0.17^{\mathrm{A}}$ \\
\hline $\begin{array}{l}\text { How meteors, comets or asteroids may cause } \\
\text { disasters on earth }\end{array}$ & 2.63 & 0.98 & 2.72 & 1.03 & $6.9^{* *}$ & $-0.07^{A}$ \\
\hline Unsolved mysteries in outer space & 2.57 & 1.09 & 2.52 & 1.06 & $1.9^{\text {ns }}$ & $0.04^{\mathrm{A}}$ \\
\hline Why the stars twinkle and the sky is blue & 2.52 & 1.00 & 2.14 & 0.95 & $132.2^{* * *}$ & $0.32^{\mathrm{B}}$ \\
\hline How to find my way and navigate by the stars & 2.38 & 1.01 & 2.31 & 0.96 & $5.4^{*}$ & $0.06^{A}$ \\
\hline $\begin{array}{l}\text { The first landing on the moon and the history of } \\
\text { space exploration }\end{array}$ & 2.23 & 0.99 & 2.41 & 1.00 & $26.5^{\star \star *}$ & $-0.15^{A}$ \\
\hline Rockets, satellites and space travel & 2.19 & 0.99 & 2.62 & 1.01 & $168.9^{* * *}$ & $-0.35^{\mathrm{B}}$ \\
\hline $\begin{array}{l}\text { The use of satellites for communication and } \\
\text { other purposes }\end{array}$ & 1.85 & 0.85 & 2.40 & 0.97 & $325.7^{* * *}$ & $-0.51^{\mathrm{C}}$ \\
\hline
\end{tabular}

1) ns $p>0.05,{ }^{*} p<0.05,{ }^{* *} p<0.01,{ }^{* * *} p<0.001$

2) A no effect $(d<0.2),{ }^{B}$ small effect $(0.2 \leq d<0.5),{ }^{C}$ moderate effect $(0.5 \leq d<0.8),{ }^{\mathrm{D}}$ large effect $(d \geq 0.8)$

Table 3. Pupils' interest in a STS context $\left(M=2.33, M_{g}=2.06, M_{b}=2.64, \alpha=0.88\right)$.

\begin{tabular}{|c|c|c|c|c|c|c|}
\hline & \multicolumn{2}{|c|}{ Girl } & \multicolumn{2}{|c|}{ Boy } & \multirow[t]{2}{*}{$t$} & \multirow{2}{*}{$\begin{array}{l}d \\
\text { 2) }\end{array}$} \\
\hline & $M_{\mathrm{g}}$ & $S . D_{\mathrm{g}}$ & $M_{\mathrm{b}}$ & $S . D_{\mathrm{b}}$ & & \\
\hline $\begin{array}{l}\text { Inventions and discoveries that have } \\
\text { changed the world }\end{array}$ & 2.48 & 0.95 & 2.64 & 0.97 & $24.8^{* * *}$ & $-0.14^{A}$ \\
\hline $\begin{array}{l}\text { How mobile phones can send and receive } \\
\text { messages }\end{array}$ & 2.40 & 0.93 & 2.67 & 0.95 & $73.4^{* * *}$ & $-0.24^{B}$ \\
\hline How computers work & 2.21 & 0.94 & 2.87 & 0.98 & $412.0^{* * *}$ & $-0.57^{C}$ \\
\hline $\begin{array}{l}\text { How cassette tapes, CDs and DVDs store } \\
\text { and play sound and music }\end{array}$ & 2.15 & 0.92 & 2.69 & 0.98 & $281.8^{* * *}$ & $-0.47^{\mathrm{B}}$ \\
\hline How things like radios and televisions work & 2.13 & 0.89 & 2.70 & 0.94 & $337.5^{\star * *}$ & $-0.51^{\mathrm{C}}$ \\
\hline $\begin{array}{l}\text { How electricity has affected the } \\
\text { development of our society }\end{array}$ & 1.95 & 0.83 & 2.41 & 0.90 & $251.2^{* * *}$ & $-0.44^{\mathrm{B}}$ \\
\hline $\begin{array}{l}\text { The use of lasers for technical purposes } \\
\text { (CD-players, bar-code readers, etc.) }\end{array}$ & 1.90 & 0.87 & 2.72 & 0.97 & $705.4^{* * *}$ & $-0.74^{C}$ \\
\hline $\begin{array}{l}\text { How to use and repair everyday electrical } \\
\text { and mechanical equipment }\end{array}$ & 1.79 & 0.81 & 2.46 & 0.96 & $508.6^{* * *}$ & $-0.63^{C}$ \\
\hline How petrol and diesel engines work & 1.56 & 0.82 & 2.62 & 1.05 & $1128^{* * *}$ & $-0.96^{\mathrm{D}}$ \\
\hline
\end{tabular}

\footnotetext{
1) ns $p>0.05,{ }^{*} p<0.05,{ }^{* *} p<0.01,{ }^{* * *} p<0.001$

2) A no effect $(d<0.2),{ }^{\mathrm{B}}$ small effect $(0.2 \leq d<0.5),{ }^{\mathrm{C}}$ moderate effect $(0.5 \leq d<0.8),{ }^{\mathrm{D}}$ large effect $(d \geq 0.8)$
} 
Table 4. Pupils' interest in a school physics context $\left(M=2.20, M_{g}=2.03, M_{b}=2.32, a=\right.$ 0.81).

\begin{tabular}{|c|c|c|c|c|c|c|}
\hline & \multicolumn{2}{|c|}{ Girl } & \multicolumn{2}{|c|}{ Boy } & \multirow[b]{2}{*}{ 1) } & \multirow{2}{*}{ 2) } \\
\hline & $M_{\mathrm{g}}$ & $S . D_{\mathrm{g}}$ & $M_{\mathrm{b}}$ & $S . D_{\mathrm{b}}$ & & \\
\hline How the sunset colours the sky & 2.49 & 0.97 & 2.02 & 0.92 & $217.8^{\star * \star}$ & $0.40^{\mathrm{B}}$ \\
\hline Why we can see rainbows & 2.33 & 0.94 & 2.05 & 0.91 & $83.7^{\star \star *}$ & $0.25^{\mathrm{B}}$ \\
\hline $\begin{array}{l}\text { How energy can be saved or used in a more } \\
\text { effective way }\end{array}$ & 2.31 & 0.95 & 2.47 & 0.99 & $24.8^{* * *}$ & $-0.14^{A}$ \\
\hline $\begin{array}{l}\text { New sources of energy from the sun, wind, } \\
\text { tides, waves, etc }\end{array}$ & 2.29 & 0.95 & 2.37 & 0.97 & $6.1^{*}$ & $-0.07^{A}$ \\
\hline How the atom bomb functions & 2.13 & 1.03 & 2.95 & 1.02 & $576.5^{\star * *}$ & $-0.65^{\mathrm{C}}$ \\
\hline $\begin{array}{l}\text { How different musical instruments produce } \\
\text { different sounds }\end{array}$ & 2.10 & 0.95 & 2.08 & 0.98 & $0.4^{\mathrm{ns}}$ & $0.02^{\mathrm{A}}$ \\
\hline Light around us that we cannot see (IR, UV) & 1.93 & 0.85 & 2.25 & 0.94 & $113.0^{* * *}$ & $-0.30^{B}$ \\
\hline $\begin{array}{l}\text { Electricity, how it is produced and used in } \\
\text { the home }\end{array}$ & 1.86 & 0.80 & 2.35 & 0.92 & $286.6^{* * *}$ & $-0.48^{B}$ \\
\hline $\begin{array}{l}\text { Optical instruments and how they work } \\
\text { (telescope, camera, microscope, etc.) }\end{array}$ & 1.74 & 0.81 & 2.22 & 0.93 & $276.6^{\star * *}$ & $-0.46^{\mathrm{B}}$ \\
\hline How a nuclear power plant functions & 1.65 & 0.82 & 2.46 & 1.03 & $681.0^{* * *}$ & $-0.74^{C}$ \\
\hline
\end{tabular}

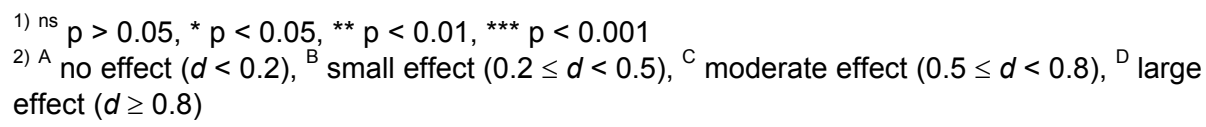

\section{Discussion}

Interest has many implications for studying and learning. It drives the pupil in a close relationship with the content or subject matter and studying leads to deep learning, which in turn allows transfer; a pupil is able to apply the achieved skills and knowledge in new situations. Although, research into pupils' attitude and interest in physics (science) originates from the 1960s and 1970s, basic questions are still open: how to make pupils' attitude towards physics more favourable and how to increase their interest in physics? (Bennett, 2003).

According to our literature review, a teacher can partly regulate the catch component of situational interest (interestingness) and pupils can also be encouraged to self-regulate interest (Krapp, 2002; Sansone, Wiebe \& Morgan, 1999; Schraw, Flowerday \& Lehman, 2001). When the teacher succeeds to catch or trigger the situational interest of his or her pupils the critical phase is how to hold it long enough so that it leads to a intrinsic motivation to study physics. According to previous studies, essential to the shift from catching to holding a pupil's situational interest are learning conditions that make the content of learning meaningful and personally relevant to pupils. In this phase pupil's affective response to teaching or learning material is also relevant. Through internalization and identification situational interest can develop to persistent topic interest. Teachers can promote the change of situational interest to personal interest by choosing of content, context and teaching methods (Schraw, Flowerday \& Lehman, 2001). Therefore, it is important for a teacher to know what content and contexts interest pupils.

\section{Boys' and girls' interest in contents and contexts}

Means of all items that belong to school physics context for both girls and boys were under the middle of the scale (2.5). Girls' means were typically lower than boys (except the items dealing with colours). These findings are in accordance with Hoffmann's (2002) results of her German survey where she emphasises that in grade 10 , only $20 \%$ of girls and $60 \%$ of boys are interested about the topics discussed in physics lessons. On the other hand, the boys' and girls' group means sug- 
gest that they are interested in the explanation of natural phenomena, like the twinkling of stars, why the sky is blue, and the changing colours of the sky during sunset. Physics in an astronomical context and astronomy in general seems to carry no gender difference: no differences of moderate or large size were observed between girls and boys in Table 2 .

The boys' group means on Tables 3 and 4, indicate an interest towards the understanding and use of electrical and mechanical equipment, such as satellites, petrol and diesel engines, laser, radio, television, and computers. On the other hand, the less interesting things for girls in all tables were connected in some way to artefacts and technological processes: The use of satellites for communication and other purposes; How petrol and diesel engines work; and How a nuclear power plant functions. This is also similar to Hoffmann's (2002) results. She pointed out that in the STS context the ratio between boys and girls was at the same level.

Girls were more interested than boys in phenomena not easily or not at all explained by school physics (moderate effect between girls and boys as shown in Table 1). It is clear that pupils' interests in fantasy context belong to the feeling or affective related valences of interest and are associated with a topic for instance, feelings of enjoyment and involvement (Schiefele, 1991, 1999).

Based on Tables 2-4 the most interesting things (especially for girls) in all contexts were connected in some way to being a human being: How it feels to be weightless in space; [Human] inventions and discoveries that have changed the world; and Why we can see rainbows. The results are in accordance with the findings of Uitto, Juuti, Lavonen, and Meisalo (2005) from the same ROSE FIN data that more than boys, girls were interested in the contents and context of human biology and health education.

The results presented in Tables 2-4 do not corroborate the hypothesis that STS, Applications-led or science for all approaches were felt interesting by pupils. Pupils were not so interested in understanding about skills where they might need to think and act scientifically as a member of the local, national and global communities (How electricity has affected the development of our society; Electricity, how it is produced and used in the home). This kind of socially oriented context seems not as interesting as context connected to being a human being. However, from the same ROSE FIN data Uitto, Juuti, Lavonen, and Meisalo (2004) found that girls attitudes to nature values and environmental responsibility were stronger than those of boys, which may indicate that in the societal or STS context, girls could be interested in physics education in the context of environment or sustainable development such as the production of renewable energy sources. Therefore, it is no wonder that technology is no longer so important in STS approach, originally emphasising links between science, technology and society by means of emphasising from the point of view of technology for example the following: a technological artefact, process or expertise; the interactions between technology and society (Aikenhead, 1994, pp. 52-53). An interesting example in the direction of human being context and society and life sciences orientation can be found in a new textbook "AS Science for Public Understanding" (Hunt \& Millar, 2000).

\section{Challenges for curriculum and textbook development}

Our research findings indicate at least four challenges for curriculum and textbook development. Typically it has been assumed that the context where science is discussed in situations of everyday life is interesting for pupils. Our survey indicates that phenomena that do not belong to everyday life are more interesting. Is it possible to discuss about physics also in fantasy context? According to Malone and Lepper (1987) fantasy contexts can be intrinsic/endogenous and extrinsic/exogenous to the content to be learned. In endogenous fantasy, the content to be learned is embedded in the fantasy context, e.g., the skill to be learned and the fantasy are related to each other. In exogenous fantasy, the relationship between the content of the study and the fantasy is purely 
arbitrary. For example, it might be possible that a physics teacher can explain what the origins of the horoscope are or how phenomena that are paranormal have been researched.

The second challenge is to clarify how astronomy content and physics in astronomy contexts can be increased in school physics. This is in parallel with findings of Osborne and Collins (2001). They indicated also that pupils would like to learn more about the solar system and the universe in physics. For example, it should be designed how physics can be taught in the astronomy context and how teaching of pure astronomy can be increased. There is a wide spectrum of topics that could be approached in this context from kinematics to electromagnetic radiation and nuclear fusion. Discussion on satellites, space research and especially space exploration seem to be very exciting topics for pupils. Moreover, astrobiological topics like extraterrestrial life, seem to be interesting for pupils. This kind of plan needing more study time might be realistic in Finland, since there is one extra hour for lower secondary physics and chemistry in the new core curriculum for basic education (NBE, 2004) in comparison with the old one.

The third challenge is to increase human being context, health education and examples of life sciences to physics teaching. For example, ergonomics or anatomy and functioning of the human body might be possible areas. Especially, in the textbooks too often ideal "bodies" are moving, warming up or absorbing radiation. It is valuable if phenomena can be connected to real contexts pupils are interested about or what concerns directly themselves, e.g., human beings and especially pupils themselves in everyday life, sports or hobbies, animals like pets they have or plants they see in their surroundings. In biology contents, there are numerous fascinating phenomena that are directly influenced by some physical phenomena. These phenomena could be used as learning contexts in physics, such as the extreme conditions of specific life forms in the deep sea or high on the mountains and within ice or hot springs. Some physical conceptions can be used in the context of various records of animals and plants (mass, weight, volume, acceleration, velocity, kinetic energy etc.) instead of machines or cars or various physical instruments.

The fourth challenge is technology teaching. Boys like to know how technical applications work and other issues in STS context. This kind of technical knowledge does not interest most girls. On the other hand, considering youngsters' future, technical applications play a core role in further studies in schools of technology (vocational schools, polytechnics or universities). Thus, it is important to find more versatile approaches to show technical application's interestingness and importance for all pupils. Everyone uses technical applications; therefore, usability testing and user-centred design could be interesting study contexts. Further, it would be useful to make an intervention study on pupils' motivation and learning physics in the context where technological context is combined with human being context or astronomical context. A good example of integration of human context with technological context can be seen in a college level physics textbook written by Cutnell and Kenneth (2004).

In Finland, the beginning of the 21st century is an interesting time in the field of technology teaching. In the national framework curriculum of 2005, the goals and contents for technology teaching are described for the first time as a cross-curricular theme "Technology and the Individual" and it will be taught by being integrated in several subjects, such as Educational Handicraft (Handicraft or Craft for short), Physics, Chemistry, Biology and Home Economics. (NBE, 2004). The goal of the theme is to help the pupil both to understand the individual's relationship to technology, and to see the importance of technology in our daily lives. Therefore, there is great potential to change the shape of technology teaching in schools. Based on our survey both genders are quite interested, for example, to know how energy can be saved or used in more effective ways, or to know how inventions and discoveries have changed the world. These themes can be discussed for example through core contents of technology, mentioned in the curriculum: "the 
technology and society of the future", "technology-related issues of ethics, morality, well-being, and equality" and "the development of technology and the factors affecting that development in different cultures, in various spheres of life, in different eras". Further, pupils are competent to act in everyday life. Perhaps, pupils do not see what interesting everyday situations could offer. Pupils are interested in fantasy context. The reason could be that then pupils feel more competent to regulate their own life.

\section{Challenges for teacher education}

Challenges discussed in the previous chapter should also be discussed in teacher education. In Finnish teacher education, especially, the goal is to reach the "teacher as researcher and autonomous developer of her work" ideal. It means that the outcomes of this study summarized above should be made available to teachers. Even other recent research supporting our conclusions can be found and included in the course materials for teachers. For instance, Hannula (2005) in her doctoral dissertation clarifies conditions for astronomy teaching in Finland. According to her thesis, the lower secondary school teachers' attitudes have been positive to astronomy teaching. However, the teachers have felt uncertainty about their competence and they have worried about lack of learning materials and the equipment available to them. There are great challenges for inservice and pre-service education of physics teachers as well as for development of curricula and learning materials.

\section{Generalisations and further challenges}

Based on the findings of the present study, it is worthwhile being aware of the fact that boys and girls as groups have different interests in specific contents and contexts. From the viewpoint of physics teaching and learning it is important to know how to hold part of situational interest long enough to lead to a motivation to study and the activities of studying. We summarised in the introduction that interest is related to affective response, affect is related to persistence in studying, and studying is related to learning (Ainley, Hidi \& Berndorff, 2002). Preliminary results of the ROSE FIN survey indicate that Finnish results may be general to the countries having the human development index at the same level as Finland does. We suggest developers of curricula and textbook authors, who have a lot of freedom in choosing different approaches and especially contexts, for certain topics to take the result seriously and implement certain contents and contexts. In practice classroom situations and learning materials can form the link between interest and learning. Selected approaches and learning materials should show that science is useful both in everyday life and in further studies and occupations.

It is important to understand that the findings of the survey are not absolute; they reflect presentday general trends among young people's perceptions and experiences. Results reflect the objects of interest of Finnish boys and girls and the world they experience in relation to science as measured with the ROSE FIN questionnaire. However, the situation in developing countries seems to be different, there modern technologies seem to have much relevance as possible solvers of local problems as indicated by the international ROSE INT survey (Schreiner \& Sjøberg, 2004).

Results of this research do not explain how situational interest develops into a long-standing personal interest (see e.g., Alexander \& Jetton, 1996; Krapp, 2002). It seems self-evident that teachers must first think how they can "catch" and "hold" situational interest during their physics lessons. One interesting new approach to physics education could be developed by combining technological and human or astronomical contexts.

Quantitative measurements have been criticised in general, and when based on surveys, it is difficult to understand in detail the structure of pupils interests (Osborne, Simon, \& Collins, 2003). On the other hand, surveys like this research yield information about the significance of studied phenomena. In the present research, the survey gave information about pupils' interest in 
different contents and contexts and helped to evaluate how significant the differences are between boys' and girls' interests. There is clearly a need to explore in much more detail the effect on pupils following particular types of science courses and using particular types of learning materials. Therefore, we are planning intervention studies with the aim of clarifying how the choice of context has an influence on (catch) pupils situational interest in physics and how this interest can be held. More detailed evaluation of the effects of specific components of context-based approaches and learning materials are needed. In these further studies one interesting possibility is to follow suggestions of Schraw and Lehman (2001): Teachers should 1) offer meaningful choices to pupils, 2) use well-organised texts, 3) select texts that are vivid, 4) use texts that pupils know about, 5) encourage pupils to be active learners, and 6) provide relevance cues for pupils.

\section{ACKNOWLEDGEMENTS}

The ROSE-FIN survey was funded by the European social fund (ESF), the EQUAL community initiative. We are greatly indebted to the organisers of the international ROSE Project and the National Board of Education, as well as especially to the schools and teachers collaborating with us.

\section{REFERENCES}

Aikenhead, G. (1994). What is STS teaching? In J. Solomon, G. Aikenhead (Eds.), STS Education: International Perspectives On Reform (pp. 52-53). New York: Teachers College Press.

Ainley, M., Hidi, S., \& Berndorff, D. (2002). Interest, learning, and the psychological processes that mediate their relationship. Journal of Educational Psychology, 94, 545-561.

Alexander, P.A., \& Jetton, T.L. (1996). The role of importance and interest in the processing of text. Educational Psychology Review, 8, 89-12.

Asgari, M., \& Kaufman, D. (2004). Relationships Among Computer Games, Fantasy, and Learning. Proceedings of he $2^{\text {nd }}$ International Conference on Imagination and Education. Retrieved August 15, 2005, from http://www.ierg.net/confs/2004/

Bailey, J.M., \& Slater, T.F. (2003).A Review of Astronomy Education Research. The Astronomy Education Review, 2(2), 20-45.

Bennett, J. (2003). Teaching and Learning Science: A Guide to Recent Research and its Applications. London: Continuum.

Bennett, J., Hogarth, S., \& Lubben, F. (2003). A systematic review of the effects of context-based and Science-Technology-Society (STS) approaches in the teaching of secondary science. Version 1.1 In: Research Evidence in Education Library. London: EPPI-Centre, Social Science Research Unit, Institute of Education.

Biklen, S.K., \& Pollard, D. (2001). Feminist Perspectives on Gender in Classrooms. In V. Richardson (ed.), Handbook of research on teaching (pp. 723-747). Washington, DC: American Educational Research Association.

Cohen, J. (1988). Statistical power analysis for the behavioral sciences (2nd ed.). Hillsdale, NJ: Lawrence Earlbaum Associates

Cordova, D.I., \& Lepper, M.R. (1996). Intrinsic motivation and the process of learning: Beneficial effects of contextualization, personalization, and choice. Journal of Educational Psychology, 88, 715-730.

Cutnell, J.D., \& Kenneth, W.J. (2004). Physics, 6th Edition. New York: John Wiley \& Sons Inc.

Deci, E.L., \& Ryan, R.M. (1985). Intrinsic motivation and self-determination in human behavior. New York: Plenum Press.

Hannula, I. (2005). Need and possibilities of astronomy teaching in the Finnish comprehensive school. Report Series in Physics, University of Helsinki, HU-P-D124. Retrieved August 15, 2005, from http://ethesis.helsinki.fi/julkaisut/mat/fysik/vk/hannula/ 
Hidi, S. (1990). Interest and its contribution as a mental resource for learning. Review of Educational Research, 60, 549-571.

Hidi, S., Renninger, A., \& Krapp, A. (2004). Interest, a motivational variable that combines affective and cognitive functioning. In D.Y. Dai \& R.J. Sternberg (Eds.), Motivation, emotion, and cognition. (pp. 89-115). Mahwah, NJ: Lawrence Erlbaum.

Hodson, D. (2003). Time for action: Science education for an alternative future. International Journal of Science Education, 25(6), 645-670.

Hoffman, L. (2002). Promoting girls' interest and achievement in physics classes for beginners. Learning and Instruction, 12, 447-465.

Hunt, A., \& Millar, R. (2000). AS Science for Public Understanding. Oxford: Heinemann Educational Books - Secondary Division.

Krapp, A. (2002). Structural and dynamic aspects of interest development: theoretical considerations from an ontogenetic perspective. Learning and Instruction, 12, 383-409.

Krapp, A. (2003). Interest and human development - an educational-psychological perspective. British Journal of Educational Psychology. Monograph Series II (2) Development and Motivation: Joint Perspectives, 57-84.

Lepper, M.R., \& Henderlong, J. (2000). Turning "play" into "work" and "work" into "play": 25 years of research on intrinsic versus extrinsic motivation. In C. Sansone \& J.M. Harackiewicz (Eds.), Intrinsic and extrinsic motivation: The search for optimal motivation and performance (pp. 257-307). San Diego: Academic Press.

Malone, T., \& Lepper, M. (1987). Making learning fun: A taxonomy of intrinsic motivations of learning. In R.E. Snow \& M.J. Farr (Eds.), Aptitude, learning, and instruction: Vol. 3. Conative and affective process analyses (pp. 223-253). Hillsdale, NJ: Lawrence Erlbaum.

Mitchell, M. (1993). Situational interest: Its multifaceted structure in the secondary school mathematics classroom. Journal of Educational Psychology, 85, 424-436.

NBE (National Board of Education) (1994). Framework curriculum for the comprehensive school (in Finland). Helsinki: State Printing Press and National Board of Education.

NBE (National Board of Education) (2004). National core curriculum for basic education (in Finland), Helsinki: National Board of Education.

Osborne, J., Simon, S. \& Collins, S. (2003). Attitudes towards science: a review of the literature and its implications. International Journal of Science Education, 25(9), 1049-1079.

Osborne, J., \& Collins, S. (2001). Pupils' views of the role and value of the science curriculum: A focus-group study. International Journal of Science Education, 23(5), 441-67.

Parker, L.E., \& Lepper, M.R. (1992). Effects of fantasy contexts on children's learning and motivation: Making learning more fun. Journal of Personality and Social Psychology, 62, 625-633.

Ryan, R.M., \& Deci, E.L. (2000). Intrinsic and extrinsic motivations: Classic definitions and new directions. Contemporary Educational Psychology 25, 54-67.

Sansone, C., Wiebe, D. J., \& Morgan, C. (1999). Self-regulating interest: The moderating role of Hardiness and Conscientiousness. Journal of Personality, 61, 701-733

Schiefele, U. (1991). Interest, learning, and motivation. Educational Psychologist, 26, 299-323.

Schiefele, U. (1992). Topic interest and levels of text comprehension. In K.A. Renninger \& A. Krapp (Eds.), The role of interest in learning and development (pp. 151-182). Hillsdale, New Jersey: Lawrence Erlbaum.

Schiefele, U. (1999). Interest and learning from text. Scientific Studies of Reading, 3, 257-279.

Schraw, G., \& Lehman, S. (2001). Situational interest: a review of the literature and directions for future research. Educational Psychology Review, 13, 23-52.

Schraw, G., Flowerday, T., \& Lehman, S. (2001). Increasing situational interest in the classroom. Educational Psychology Review, 13, 211-224.

Schreiner, C., \& Sjøberg, S. (2004). Sowing the seeds of ROSE. Background, Rationale, Questionnaire Development and Data Collection for ROSE (The Relevance of Science Education) - a comparative study of students' views of science and science education. Acta Didactica, 4. Oslo: Dept. of Teacher Education and School Development, University of Oslo. 
Simon, S. (2000). Students' attitudes towards science. In M. Monk, \& J. Osborne (Eds.), Good practice in science teaching: What research has to say (pp. 104-119). Buckingham: Open University Press.

Sjøberg, S. (2000). Interesting all children in 'science for all'. In R. Millar, J. Leach \& J. Osborne (Eds.), Improving Science Education: The Contribution of Research. Buckingham: Open University Press.

Stokking, K.M. (2000). Predicting the choice of physics in secondary education. International Journal of Science Education 22(12), 1261-1283.

Uitto, A., Juuti, K., Lavonen, J., \& Meisalo, V. (2005). Is pupils' interest in biology related to their out-of-school experiences? In V. Zogza (Ed.), Proceedings of the 5th ERIDOB (European Researchers in Didactik of Biology) Conference. Patras, Greece.

Uitto, A., Juuti, K., Lavonen, J., \& Meisalo, V. (2004). Who is responsible for sustainable development? Attitudes to environmental challenges: A survey of Finnish 9th grade comprehensive school students. In A. Laine, J., Lavonen, \& V. Meisalo (Eds.), Current research on mathematics and science education. Proceedings of the XXI annual symposium of the Finnish Association of Mathematics and Science Education Research. University of Helsinki, Department of Applied Sciences of Education. Research Report 253, 80-102.

Volet, S., \& Järvelä, S. (2001). Motivation in learning contexts. Theoretical advances and methodological implications. Amsterdam: Pergamon.

Zeilik, M., Bisard, W., \& Lee, C. (2002). Research-Based Reformed Astronomy: Will It Travel? The Astronomy Education Review, 1(1), 33-46. 